\title{
Experimental Evaluation of Engineered Cementitious Composites as Reflective Crack Control Interlayer for Composite Pavements
}

\author{
Mohammad Bhuyan ${ }^{1}$, Mohammad Khattak $^{1, *}$, Qian Zhang ${ }^{1}$, and Emilee Schlader ${ }^{2}$ \\ ${ }^{1}$ Department of Civil Engineering, University of Louisiana at Lafayette, LA70503 \\ ${ }^{2}$ Department of Architectural Engineering, Missouri University of Science and Technology
}

\begin{abstract}
Reflective cracking at transverse joints is considered as a predominant distress in composite pavements. Various interlayers have been used previously to prevent or retard reflective cracking. Engineered cementitious composite (ECC) is a special type of high-performance fiber-reinforced cementitious material that is expected to perform better as an interlayer due to its higher tensile strength and ductility. This study aims to evaluate the effectiveness of ECC as an interlayer system experimentally. A laboratory test protocol was designed to simulate repeated traffic loads to measure the fatigue performance of ECC interlayer system using digital image correlation (DIC) technique. It was found that the composite pavement specimens with ECC interlayer provided significantly higher fatigue life as compared to the control specimens without interlayer. This result indicates that ECC could be used as a potential effective interlayer system to retard or mitigate reflective cracking.
\end{abstract}

\section{Introduction}

When hot mix asphalt (HMA) layer is constructed over an existing Portland cement concrete (PCC) layer, significant tensile strain originates at the bottom of the HMA at transverse joints. Such strains are caused due to high stress concentration from heavy traffic loads, changing temperature, and lack of base support. Overtime these tensile strains accumulate and result in micro crack in the HMA at the transverse joint, which then transform into macro cracks and propagates upward and hence termed as reflective cracking. The reflective cracking is one of the most common causes of composite pavement deterioration [1]. Utter prevention of reflective cracking is not yet invented, although several methods have been suggested to decelerate its formation and propagation [2].

Generally, saw and seal, chip seal, fiberglass grid, SAMI, STRATA, and fabrics have been used as interlayers between PCC and overlaid HMA to retard reflective cracking. Elseifi et al. [3] found that saw and seal, chipseal has shown improvement of service life however fiberglass grid decreased service life when used as interlayer. SAMI, STRATA, and fabrics showed mixed results as interlayer for composite pavements. Amini [4] evaluated the performance of paving fabrics to delay reflective crack propagation. He found that fabrics improved pavement life in general, but there were cases where fabrics provide little or no improvement. Gonzalez-Torre et al. [5] demonstrates the effectiveness of geosynthetics as an anti-reflective cracking system for different load frequencies using laboratory experiments. In their research, geosynthetics were found to be effective interlayer system at low frequency loads but not at high frequency loads. Moreno-Navarro et al. [6] showed how deconstructed tires could increase fatigue life of pavements if used as an interlayer. They recommended this material as an alternative interlayer as it provides significant increase in fatigue life of test specimen. Using composite specimen interface cracking tests, the efficiency of asphalt rubber membrane interlayer (ARMI) was examined by Chen, Lopp and Roque [7]. They found that ARMI cannot delay reflective cracking. Sudarsanan et al. [8] assessed the performance of jute woven and nonwoven geotextiles as interlayers through a series of laboratory experiments. Only jute woven geotextiles had shown some potential ability to retard reflective cracking. However, nonwoven geotextiles did not show significant prospective to be an interlayer as it could not delay reflective cracking. Fiberglass grid performance was investigated by Fallah and Khodaji [9] where it shows significant improvement of fatigue life under repeated loading cycles. Khodaii et al. [2] has also evaluated the performance of geogrid on asphalt pavement to retard reflective cracking. They reported that geogrid provided maximum life when it was placed at a one-third depth of overlay thickness from the bottom.

From the review of literature, it is obvious that many researchers are evaluating the performance of different materials as interlayer system. As engineered cementitious composites (ECC) is a probable material to be used as an interlayer due to its higher ductility and strength, this study is dedicated to evaluate the performance of ECC as an interlayer. ECC is a special kind of fiber reinforced composite that exhibits strain

* Corresponding author: khattak@louisiana.edu 
hardening behavior and high ductility under tension [10, 11]. Unlike conventional concrete, ECC forms multiple tight cracks under tension before final fracture, which leads to high deformation capacity and fracture resistance. Studies also showed that using ECC as overlays for repair of bridge deck and rigid pavement successfully suppressed reflective cracking and dramatically extended the fatigue life [12-19].

Although ECC overlays have been demonstrated to be effective, constructing the entire overlay using ECC would be costly. Therefore, in this study, a thin precast layer of ECC would be placed between the existing PCC pavement and the HMA overlay just above the transverse joints. It is hypothesized that the ECC overlay would arrest the reflective cracking so that the HMA overlay constructed above the interlayer would not be affected by reflective cracking.

\section{Materials and specimen preparation}

\subsection{Hot mix asphalt (HMA)}

Superpave mixture design was conducted for HMA mixture. The mix design yielded $4.75 \%$ optimum asphalt content for target air void of 4\%. PG64-22 and limestone aggregates were acquired from local contractor. The aggregate gradation used for HMA mixture is shown in Table 1.

Table 1. Aggregate gradation used for the HMA mix.

\begin{tabular}{|c|c|}
\hline Sieve (mm) & Passing (\%) \\
\hline 12.5 & 100 \\
\hline 9.5 & 94 \\
\hline No. 4 & 85 \\
\hline No. 8 & 68 \\
\hline No. 16 & 46 \\
\hline No. 30 & 25 \\
\hline No. 50 & 14 \\
\hline No. 100 & 8 \\
\hline No. 200 & 3 \\
\hline
\end{tabular}

\subsection{HMA beam specimen}

HMA beam specimens of $51 \mathrm{~mm} \times 51 \mathrm{~mm} \times 305 \mathrm{~mm}$ were prepared using $90 \mathrm{kN}$ (20 kip) dynamic press machine. The loose HMA mixture heated at compaction temperature of $150^{\circ} \mathrm{C}$ was poured into a steel mold. Top plate of dynamic press machine was allowed to sit on the steel compaction beam and then a ramp load of $20 \mathrm{kN}$ was slowly applied. After initial compaction, a cyclic load using Haversine waveform was applied, where maximum and minimum loads were $65 \mathrm{kN}$ and $2 \mathrm{kN}$, respectively. The cyclic load over the specimen was released after required thickness to achieve target density was obtained. The above procedure yielded uniform beam specimens of about $51 \pm 2 \mathrm{~mm}$ thickness and air void content of $4 \pm 0.25 \%$.

\subsection{Engineered cementitious composite (ECC)}

The material used to develop ECC mixture are Type 1 Portland cement, class F fly ash, river sand, water, high range water reducing admixture, and Polyvinyl Alcohol (PVA) fibers. The mix proportion is summarized in Table 2 [20].

Table 2. Mix design of ECC $\left(\mathrm{kg} / \mathrm{m}^{3}\right)$.

\begin{tabular}{|c|c|}
\hline Mix ID & FA 3.2 \\
\hline Cement & 302 \\
\hline Fly Ash & 965 \\
\hline River Sand & 467 \\
\hline Water & 329 \\
\hline Admixture & 3.6 \\
\hline PVA Fiber (2\% by Volume) & 26 \\
\hline
\end{tabular}

In order to construct ECC, all the solid ingredients were thoroughly dry-mixed for 2 min. Water was then gradually added and mixed for another 2 min followed by water reducer agent as per need to achieve flowable paste. After reaching the required consistency, fibers were added slowly and mixed carefully for another 4 to 6 min. The mixture was then poured on plate molds of $305 \mathrm{~mm} \times 51 \mathrm{~mm} \times 12.5 \mathrm{~mm}$ to prepare $12.5 \mathrm{~mm}$ and 6.25 $\mathrm{mm}$ thick ECC specimens. The ECC used in this study was designed based on locally available material with an average tensile strength of $2.4 \mathrm{MPa}$ and tensile strain capacity of $2.5 \%$. All specimens were cured for 14 days under standard laboratory conditions $\left(23 \pm 3^{\circ} \mathrm{C}\right.$ and $50 \pm 10 \%$ relative humidity) sealed in plastic sheet.

\subsection{Portland cement concrete (PCC)}

A quick mix concrete was used to prepare $51 \mathrm{~mm} \mathrm{x}$ $51 \mathrm{~mm} \times 152 \mathrm{~mm}$ PCC beam as base layer for the interlayer specimens. Two such beams $6 \mathrm{~mm}$ apart were placed underneath the control HMA or ECC interlayer, representing a PCC joint under HMA layer.

Control HMA and ECC Interlayer Composite Specimen. To prepare the control specimen, the HMA and two PCC beams were preheated at $145^{\circ} \mathrm{C}$ for 30 min. The HMA beam was then bonded to the two PCC beams (6 $\mathrm{mm}$ joint at the center) using a thin layer of preheated PG64-22 asphalt binder as a tact coat (Figure 1). A $15 \mathrm{~kg}$ sustained load was placed on the top of HMA layer for $45 \mathrm{~min}$ to achieve adequate adhesion. In order to prepare the interlayer specimen, the preheated HMA beam was bonded with the ECC interlayer beam using preheated asphalt binder as before. The ECC beam was not heated unlike the PCC beam of control specimen. The HMA and ECC combined beam was then bonded with two PCC beams using epoxy glue. It should be noted that center span of about $150 \mathrm{~mm}$ for ECC beam was not bonded with PCC to utilize maximum strain capacity of ECC interlayer. The combined thickness of ECC and HMA was always maintained at $50 \mathrm{~mm}$. HMA beams thickness was reduced by a saw-cut before it was bonded to ECC. Figure 1 shows a schematic image of an ECC Interlayer specimen. 


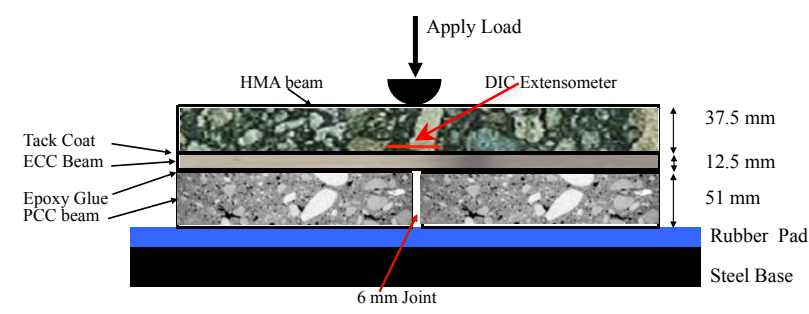

Fig. 1. Schematic image for the ECC interlayer specimen.

\section{Test methods}

\subsection{Digital image correlation (DIC)}

DIC technique is one of ways to measure any strain at any direction on a 2D plane for a test specimen. Researchers have been using this technique to measure strain development and propagation on laboratory test specimens recently. In this technique, specimen face is painted with densely spread black dots on a white background. From the respective displacement of black dots (in any direction) on white surface strain could be measured from consequent images at the time loading and unloading. Hence, horizontal/vertical or shear strains could be measure by consequent images of the surface and could be corresponded to loading. Using this technique, a virtual extensometer could be put on any direction and strain could also be measured at that direction [21, 22]. Several researchers have used this DIC technique to study the strain development and propagation in different types of interlayers on pavements. With the help of the DIC technique, they also estimated fatigue lives of test specimens for performance measure of interlayer [23-26].

In this research, the DIC technique has been implemented to study the strain development and crack propagation of HMA layer with or without ECC interlayer. With the help of the DIC technique, fatigue lives of the specimens were also measured and performance of ECC was evaluated.

\subsection{Flexural ramp loading test}

At first, a flexural ramp loading test was performed on both ECC and control specimens to understand and compare the reflective crack development and propagation pattern. Specimens were supported uniformly by $12.5 \mathrm{~mm}$ thick rubber pad. The rubber pad was resting on a $50 \mathrm{~mm}$ thick steel base. A point load was applied at the center of the specimen at a rate of 0.5 $\mathrm{mm} / \mathrm{min}$ (Figure 1). With help of DIC camera, images were taken at every $0.25 \mathrm{~s}$ interval. These images were used to analyze horizontal strain distribution for the test. Triplicate specimens were tested for control, $6.25 \mathrm{~mm}$, and $12.5 \mathrm{~mm}$ thick ECC interlayer under HMA beam.

\subsection{Flexural fatigue test}

Haversine load waveform with $0.1 \mathrm{sec}$ of load-unload period and $0.5 \mathrm{sec}$ of rest period was used for fatigue test. Maximum and minimum applied cyclic loads were $1.0 \mathrm{kN}$ and $0.1 \mathrm{kN}$, respectively. The repeated load was applied until a complete failure of the specimen. While test was being conducted, continuous DIC images were obtained using the camera with an interval of $60 \mathrm{sec}$. With the help of DIC images, horizontal tensile strain map was drawn and cumulative tensile strains were calculated to determine fatigue life for each specimen.

\section{Results and discussion}

\subsection{Horizontal tensile strain map from ramp loading test}

For the flexural ramp-loading test, the horizontal tensile strain $\left(\mathrm{Exx}^{t}\right)$ map obtained from DIC is shown in Figure 2. Three different time points from the beginning of the test were chosen $(\mathrm{T} 1=90 \mathrm{sec}, \mathrm{T} 2=240 \mathrm{sec}, \mathrm{T} 3=420$ $\mathrm{sec}$ ) for $\mathrm{Exx}^{\mathrm{t}}$ map as shown in the figures. It is worth mentioning that this strain is a total strain, which comprises elastic, plastic and viscous strain. Flexural Stress (o) at the bottom of HMA layer corresponding to time is calculated and mentioned in the figure. It is clear that without any ECC interlayer, one single reflective crack propagates from bottom to top, whereas with the presence of ECC interlayer, multiple cracks propagate from the bottom of HMA and they join together at the time of failure. Furthermore, DIC images did not detect any crack in ECC interlayer at failure. It was found that the ECC interlayer specimens showed higher flexural stress level at failure (14 MPa) as oppose to the control specimens which failed at stress level of $8.6 \mathrm{MPa}$.

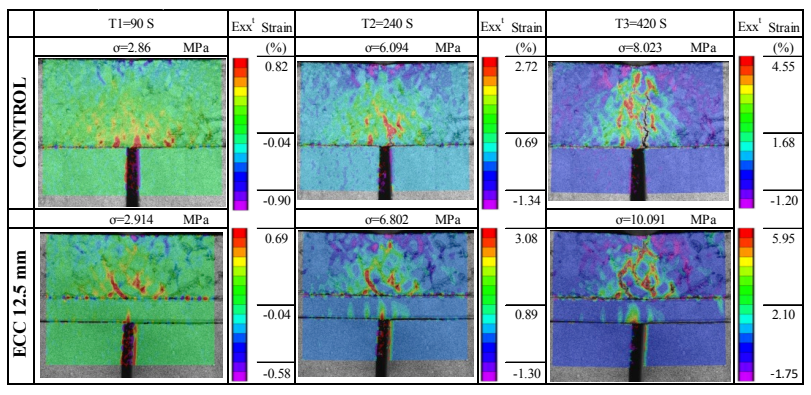

Fig. 2. Distribution of horizontal tensile strain $\left(\operatorname{Exx}^{t}\right)$ for control and ECC Interlayer specimens.

\subsection{Fatigue life}

From the fatigue test specimens, the cumulative horizontal tensile strain $\left(\mathrm{Exx}^{\mathrm{c}}\right)$ is calculated from DIC images for each cycle at the bottom of the HMA layer. Location of virtual extensometer for $\mathrm{Exx}^{\mathrm{c}}$ calculation is shown in Figure 1 by a red line at the center-bottom of HMA layer. Figure $3 \mathrm{a}$ illustrates a comparison of cumulative horizontal tensile strains $\left(\mathrm{Exx}^{\mathrm{c}}\right)$ as a function of load cycles for both ECC interlayer and control specimens. 

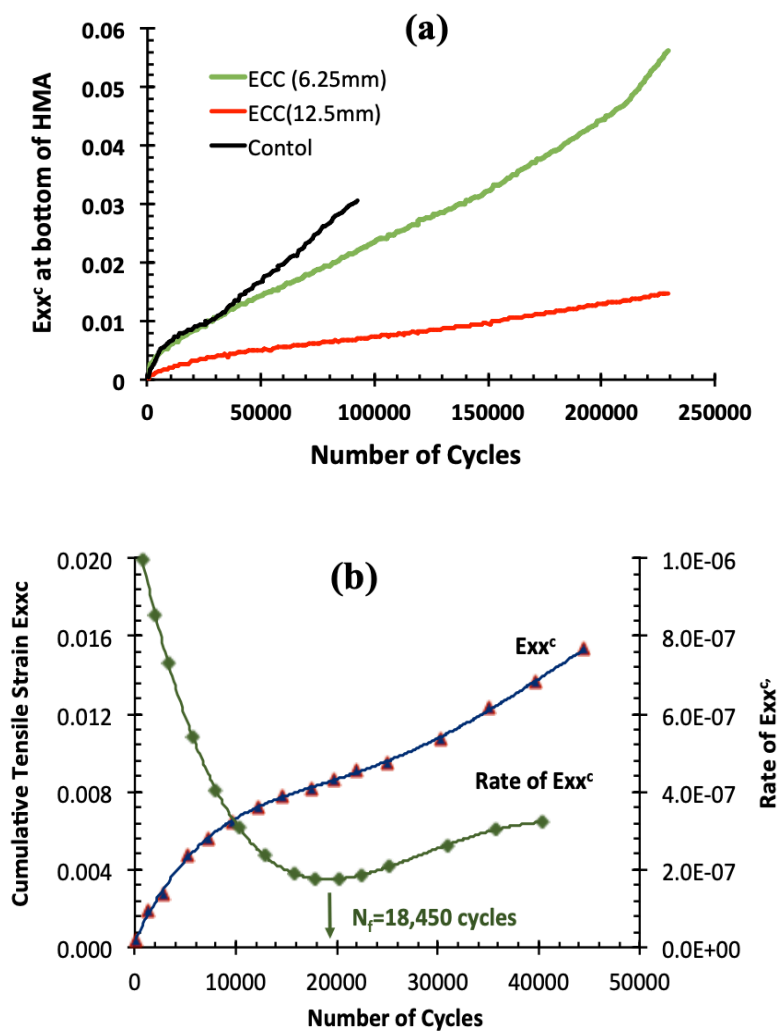

Fig. 3. (a) Cumulative tensile strain comparison, (b) fatigue life determination.

It can be seen in Figure 3a that for the same load cycle, the thicker ECC interlayer of $12.5 \mathrm{~mm}$ exhibited significantly lower $\mathrm{Exx}^{\mathrm{c}}$ values as compared to the control ones. Similarly, for the thinner ECC interlayer of $6.25 \mathrm{~mm}$ the $\mathrm{Exx}^{\mathrm{c}}$ values were lower than the control specimens during higher load cycles. Since the accumulation of tensile strain at the bottom of HMA layer was much lower for ECC interlayer system, it is expected that the fatigue life (Nf) for such mixtures will be much higher. In order to determine fatigue life, $\mathrm{Exx}^{\mathrm{c}}$ was plotted against the number of load cycles for each specimen as shown in Figure $3 b$. The rate of strain accumulation was calculated and then plotted as function of load cycles. It can be seen that the rate of accumulation decreased first, reached a minimum value and then started to increase. It is assumed that the increase in the rate is due to micro crack initiation and propagation. The number of load cycles at which the rate of cumulative tensile strain just started to increase was reported as fatigue life of the specimen as shown in Figure $3 \mathrm{~b}$. The fatigue lives of the control and ECC interlayer specimens were determined and compared as shown in Table 3. It is obvious that the ECC interlayer specimens exhibited approximately $70 \%$ and $140 \%$ average increase of fatigue lives, for $6.25 \mathrm{~mm}$ and 12.5 $\mathrm{mm}$ thick ECC, respectively. This indicates that the ECC interlayers were successful in distributing the stresses to a wider area. Thus, resulting in lower tensile strains at the bottom of HMA layer and delaying the micro crack initiation, formation of macro cracks and propagation as reflective cracks.
Table 3. Summary of fatigue life of control and ECC interlayer systems.

\begin{tabular}{|c|c|c|}
\hline Specimen Type & Average & Standard Deviation \\
\hline Control & 27,400 & 8,950 \\
\hline ECC interlayer $6.25 \mathrm{~mm}$ & 46,500 & 750 \\
\hline ECC interlayer $12 \mathrm{~mm}$ & 65,000 & 1,850 \\
\hline
\end{tabular}

Map of Cumulative Horizontal Tensile Strain under Fatigue loadings. For the fatigue test specimens, the cumulative horizontal strain map comparison for control, ECC $6.5 \mathrm{~mm}$ and ECC $12.5 \mathrm{~mm}$ interlayer at 36,000 and 84,000 cycles are shown in Figure 4. By 36,000 cycles, the control specimen failed as the rate of strain $\left(\mathrm{Exx}^{\mathrm{c}}\right)$ accumulation started to increase rapidly and crack initiation was also detected by DIC. On the contrary, the ECC $6.25 \mathrm{~mm}$ specimen did not reached the fatigue life as its rate of strain $\left(\mathrm{Exx}^{\mathrm{c}}\right)$ did not start increasing by this time. The strain map is also showing that the ECC 6.5 $\mathrm{mm}$ has distributed the strains $\left(\mathrm{Exx}^{\mathrm{c}}\right)$ on a wider area in respect to the control specimen. Maximum strain level for ECC $6.25 \mathrm{~mm}$ specimen was slightly less than the control specimen at this stage. ECC $12.5 \mathrm{~mm}$ shows significantly lower maximum strain $(1.48 \%)$ at this stage and were not even nearer to fatigue life. ECC $12.5 \mathrm{~mm}$ also distributes the strains to a wider area like the 6.25 $\mathrm{mm}$ specimen.

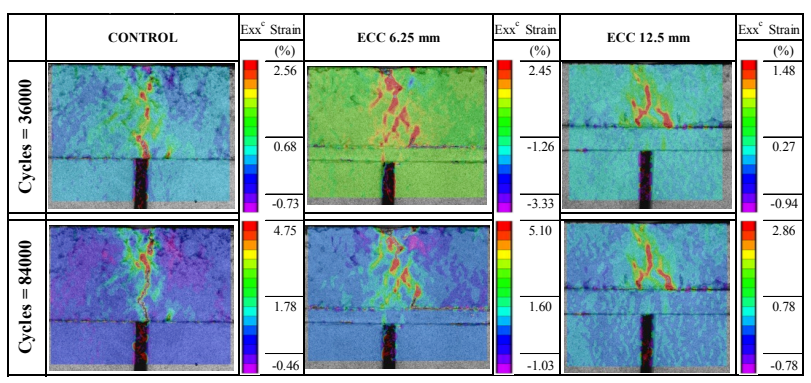

Fig. 4. Distribution of horizontal tensile strain under fatigue loading.

One single reflective crack is clearly visible at 84,000 cycles for the control specimen, but ECC $6.25 \mathrm{~mm}$ specimen did not show a full depth crack at this time although the specimen exceeded its fatigue life. This implies that ECC $6.25 \mathrm{~mm}$ specimen takes longer time to generate a full crack after the crack initiation. In other words, ECC delays the crack propagation and full crack development. Although ECC $12.5 \mathrm{~mm}$ exceeded its fatigue life at 84,000 cycles due to increased rate of strain, it shows thin crack initiation lines at this stage. It is also noticeable that ECC itself did not show any crack or plastic strain in these images.

\section{Conclusions}

Based on the results and discussion the following conclusions were made:

1. ECC interlayer significantly delays reflective crack growth by providing a firm base underneath the HMA. It was found that thicker ECC interlayer $(12.5 \mathrm{~mm})$ increased fatigue life 
by $140 \%$ while the thinner ECC interlayer ( 6.5 $\mathrm{mm}$ ) showed $70 \%$ improvement.

2. Horizontal tensile strain map as observed from DIC images for both ramp loading and fatigue test has illustrated that the ECC interlayer distributes the stress concentration at the joint to a wider area. For fatigue test, ECC reduced the tensile stress level on the bottom of HMA, which delayed reflective crack initiation, propagation and acceleration. This delay ultimately increased fatigue life of the ECC specimen. Instead of one single reflective crack as observed in the control specimen, ECC interlayer specimen generated multiple reflective cracks, which were connected with each other at failure.

3. ECC interlayer beam did not show any significant strain and crack during ramp loading and fatigue tests. It was observed that the crack initiated and propagated through the HMA only.

4. The results of the experimentation clearly indicate that ECC has high potential to be used as an interlayer system to mitigate reflective cracking in composite Pavements.

The authors would like to thank Tran-SET (Project No: 18PLSU13), National Science Foundation (NSF) under Grant Number (1757786) and University of Louisiana at Lafayette for funding this research. Special thank is also extended to Mark LeBlanc for assisting in experimentation. Any opinions, findings, and conclusions or recommendations expressed in this material are those of the author(s) and do not necessarily reflect the views of the funding agencies.

\section{References}

1. Button, J., Lytton, R. (2003). Field Synthesis of Geotextiles in Flexible and Rigid Pavement Overlay Strategies Including Cost Considerations. Texas Transportation Institute, College Station, Texas.

2. Khodaii, A., Fallah, S., Nejad, F.M. (2009). Effects of geogrid on reduction of reflection cracking in asphalt overlays. Geotextiles and Geomembranes, 27(1), 1-8.

3. Elseifi, M., Bandaru, R. (2011). Cost Effective Prevention of Reflective Cracking of Composite Pavements. Louisiana Transport Research Center.

4. Amini, F. (2005). Potential Application of Paving Fabrics to Reduce Reflective Cracking. Mississippi Department of Transportation.

5. Gonzalez-Torre, I., Galzada-perez, M.A., VegaZamanillo, A., Castro-Fresno, D. (2014). Evaluation of Reflective Cracking in pavements using a new procedure that combine loads with different frequencies. Construction and Building Materials.

6. Moreno-Navarro, F., Sol-Sanchez, M., RubioGamez, M.C. (2014). Reuse of deconstructed tires as anti-reflective cracking mat systems in asphalt pavements. Construction and Building Materials, 182-189.

7. Chen, Y., Lopp, G., Roque, R. (2013). Effects of an Asphalt Rubber Membrane Interlayer on Pavement Reflective Cracking Performance. Journal of Materials in Civil Engineering, 25(12).

8. Sudarsanan, N., Mohapatra, S.R., Karpurapu, R., Amirthalingam, V. (2018). Use of Natural Geotextiles to Retard Reflection Cracking in Highway Pavements. Journal of Materials in Civil Engineering.

9. Fallah, S., Khodaji, A. (2015). Reinforcing overlay to reduce reflection cracking; an experimental investigation. Geotextiles and Geomembranes, 43(3), 216-227.

10. Li, V.C., Want, S., Wu, C. (2001). Tensile strainhardening behavior of polyvinyl alcohol engineered cementitious composite (PVA-ECC). ACI Materials Journal, 483-492.

11. Li, V.C. (2003). On engineered cementitious composites (ECC). Journal of advanced concrete technology, 215-230.

12. Zhang, J., Li, V.C. (2002). Monotonic and fatigue performance in bending of fiber-reinforced engineered cementitious composite in overlay system. Cement and Concrete Composites, 415423.

13. Lim, Y.M., Li, V.C. (1997). Durable repair of aged infrastructures using trapping mechanism of engineered cementitious composites. Cement and Concrete Composites, 373-385.

14. Qian, S.Z., Li, V.C., Zhang, H., Keoleian, G.A. (2013). Life cycle analysis of pavement overlays made with Engineered Cementitious Composites. Cement and Concrete Composites, 78-88.

15. Yucel, H.E., Jashami, H., Sahmaran, M., Guler, M., Yaman, I.O. (2013). Thin ECC overlay systems for rehabilitation of rigid concrete pavements. Magazine of Concrete Research, 108120.

16. Zhang, Zhigang, Qian Zhang, Shunzhi Qian, Victor C. Li. (2015). Low E Modulus Early Strength Engineered Cementitious Composites Material: Development for Ultrathin Whitetopping Overlay. Transportation Research Board: Journal of the Transportation Research Board, 41-47.

17. Zhang, J., Zhenbo, W., Xiancun, J. (2013). Application of ductile fiber reinforced cementitious composite in jointless concrete pavements. Composites Part B: Engineering, 224-231.

18. Garcez, E.O., Garcez, M.R., Silva Filho, L.C.P. (2015). Application of greener engineered cementitious composites for sustainable pavement overlay design. Proceedings of 8th International Conference on Fibre Concrete, 159-169.

19. Lepech, M.D., and Li, V.C. (2010). Sustainable pavement overlays using engineered cementitious composites. International Journal of Pavement Research and Technology, 241-250.

20. Baral, K., Tatar, J., Zhang, Q. (2018). Tailoring Ductile Concrete Material with Locally Accessible 
Raw Ingredients for Transportation Infrastructure Applications. TRB 97th Annual Meeting.

21. Pan, B., Qian, K., Xie, H., and Asundi, A. (2009). Two-dimensional digital image correlation for inplane displacement and strain measurement: a review. Measurement Science and Technology, 20.

22. Nath, F., Mokhtari, and M. (2018). Optical visualization of strain development and fracture propagation in laminated rocks. Journal of Petroleum Science and Engineering, 354-365.

23. Chantachot, T., Kongkitkul, W., Youwai, S., Jongpradist, P. (2016). Behaviours of geosyntheticreinforced asphalt pavements investigated by laboratory physical model tests on a pavement structure. Transportation Geotechnics, 103-118.

24. Saride, S., and Kumar, V.V. (2017). Influence of geosynthetic-interlayers on the performance of asphalt overlays on pre-cracked pavements. Geotextiles and Geomembranes, 184-196.

25. Kumar, V.V., and Saride, S. (2018). Evaluation of cracking resistance potential of geosynthetic reinforced asphalt overlays using direct tensile strength test. Construction and Building Materials, 37-47.

26. Nath, F., Kimanzi, R.J., Kokhtari, M., Salehi, S. (2018). A novel method to investigate cementcasing bonding using digital image correlation. Journal of Petroleum Science and Engineering, 482-489. 